\title{
Role of porosity in controlling the mechanical and impact behaviours of cement-based materials
}

\author{
P. Forquin ${ }^{\mathrm{a}, *}$, A. Arias ${ }^{\mathrm{b}}$, R. Zaera ${ }^{\mathrm{b}}$ \\ ${ }^{a}$ Laboratory of Physics and Mechanics of Materials, UMR CNRS 75 54, University of Metz, Ile du Saulcy, 57045 Metz Cedex, France \\ ${ }^{\mathrm{b}}$ Department of Continuum Mechanics and Structural Analysis, University Carlos III of Madrid, Avda. de la Universidad 30, 28911 Leganés, Madrid, Spain
}

\begin{abstract}
This work deals with the influence of porosity on the tensile, the compressive and the impact behaviours of two fine cementitious mortars one with silica fume and one without. The addition of silica fume is shown to change the pore size distribution. The mix without silica fume is characterized by porosity at the scale of the grains of fine sand (approximately $100 \mu \mathrm{m}$ ), while silica fume addition results in a more porous matrix with pore sizes of millimetre length size. The mortar with silica fume shows a higher quasi static compressive and flexural strength whereas the mix without silica fume is observed to be less compressible (by irreversible reduction of volume) under heavy confinement pressure (quasi oedometric tests) and shows better ballistic performance. A numerical simulation of the impact tests employing the Krieg, Swenson and Taylor model, which accounts for both deviatoric and volumetric inelastic behaviour of the material, was undertaken using the data from quasi oedometric tests. These calculations follow the experimental results and confirm the influence of the macroscopic porosity on the impact performance of cement based materials.
\end{abstract}

Keywords: Mortar; Porosity; Confined compression; Impact behaviour; Sarcophagus configuration

\section{Introduction}

The study of the ballistic performance of concretes has led to important experimental, analytical and numerical developments in the last 10 years. Investigation has been focused on the impact of kinetic penetrators at several hundred meters per second on thick concrete targets. These penetrators, of a mass of up to 2 tonnes, formed of a highstrength steel body and a pointed nose, contain an explosive charge supposed to explode after the penetration of the intact projectile into the target [1]. The interest shown by military laboratories in this problem has escalated since the appearance in the 1980s of high or very high performance concretes (HPCs) (average failure stress under simple compression of 60-120 MPa) [2] and then to ultra-HPCs of over $200 \mathrm{MPa}$ in the 1990s [3]. The main problem was to determine whether the ballistic performance of the concretes had grown in proportion to their

\footnotetext{
${ }^{*}$ Corresponding author. Tel.: + 33387547249 ; fax: + 33387315366 .

E mail address: forquin@univ metz.fr (P. Forquin).
}

strength under simple compression and if the existing armaments were correctly dimensioned for these new materials. For example, in Fig. 1 we see how the nature of the impacted concrete can modify the structural response of the body of the missile [4].

Given the wide diversity of the parameters that characterize a projectile impact (diameter, length and mass of the projectile, radius of the pointed nose, impact velocity and angle of attack, as well as the strength, density and porosity of the concrete), it was found necessary to carry out a dimensionless study and also to carry out laboratory-scale tests of projectile impacts. These latter tests were performed with projectiles of different diameters and masses, at velocities between 200 and $1500 \mathrm{~m} / \mathrm{s}$ [5-8] (Table 1). Ordinary or HPCs were tested by Forrestal et al. [5,6], Frew et al. [7] and Gómez and Shukla [8], while Darrigade and Buzaud [4] studied the impact behaviour of ultra-HPCs. From these studies, analytical solutions were drawn that gave a prediction of the depth of penetration of a projectile into a thick concrete target, on normal impact, from the geometry and the velocity of the 


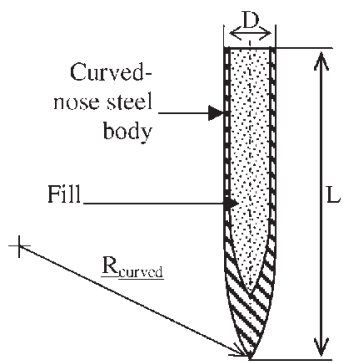

Diagram of kinetic penetrator Impact of a kinetic penetrator on a common concrete target and on one of ultra-high performance concrete (BPR300) [4]

Fig. 1. Impact of a kinetic penetrator on a thick concrete target.

Table 1

Characteristic parameters for three types of impact test

\begin{tabular}{|c|c|c|c|}
\hline $\begin{array}{l}\text { Impact type } \\
\text { Projectile type }\end{array}$ & $\begin{array}{l}\text { Kinetic penetrator impacts } \\
\text { Ogive nose steel projectile }\end{array}$ & $\begin{array}{l}\text { Laboratory impacts } \\
\text { Ogive nose steel rods }\end{array}$ & $\begin{array}{l}\text { This work } \\
\text { Flat end steel cylinder }\end{array}$ \\
\hline Projectile diameter (mm) & 150300 & 6.3530 .5 & 5.3 \\
\hline$L / D$ ratio & 520 & 6.915 & 1.51 \\
\hline Projectile mass $M(\mathrm{~kg})$ & 1502000 & 0.0151 .6 & 0.0013 \\
\hline Impact velocity $V(\mathrm{~m} / \mathrm{s})$ & 250450 & 2001430 & 750770 \\
\hline Surface kinetic energy $E_{\mathrm{c}} /\left(\pi D^{2} / 4\right)\left(\mathrm{J} / \mathrm{mm}^{2}\right)$ & 2003000 & 81600 & 16.6 \\
\hline References & [1] & {$[5,6,7,8]$} & \\
\hline
\end{tabular}

projectile. This type of dimensionless analysis was proposed especially by Kennedy [9] and by Barr [10]. From similar parameters, Forrestal et al. [5] proposed another analytical solution that was applied to metal targets (aluminium alloys) [11,12], to ordinary and to HPCs [6,7] and extended to a case of multiple impacts [8]. A synthesis of analytical solutions that were built to predict the depth of penetration of a projectile into a concrete target was recently proposed by $\mathrm{Li}$ et al. [13].

In these different models, the influence of the type of concrete on the depth of penetration is usually taken into account through its strength under simple compression. The analytical solutions were verified in the abovementioned studies for ordinary or HPCs (strength under simple compression below approximately $100 \mathrm{MPa}$ ). However, around the 'tunnel region' (the path of the projectile) the loading corresponds to a highly confined compression with a pressure level that may surpass $1 \mathrm{GPa}$, so strength under simple compression may have been inappropriate as was shown in impact tests by Hanchack et al. [14]. These tests were performed with two concretes whose strength under simple compression was very different (48 and $140 \mathrm{MPa})$. The impact tests gave similar ballistic performances. In addition, a synthesis proposed by Yankelevsky and Dancygier [15] showed that these solutions were no longer able to forecast the ballistic performance of ultraHPCs. An account of the evolution of the deviatoric strength with the hydrostatic pressure, and of the law of compaction (evolution of the pressure with the volumetric strain) had become indispensable. Related to the mechanical behaviour of concrete, the term compaction is used to define the inelastic decrease of volume at high hydrostatic pressure due to void closure. Moreover, a drop in the strength driven by a factor of equivalent strain may have to be considered [16]. More recently, Forrestal et al. [17] suggested the use of a parameter " $R$ " for the resistance of the target instead of the strength under simple compression of the concrete, this parameter to be set up for each family of impact tests. This model was used to describe the impact behaviour of ordinary concretes impacted by larger diameter projectiles $(76.2 \mathrm{~mm})[17,18]$.

Table 1 shows a comparison between the ballistic tests of this study and that reported by other authors [1,5-8]. The mass and the diameter of the projectiles used here differ significantly from those of the laboratory tests quoted above. These cylindrical projectiles of $5.3 \mathrm{~mm}$ diameters and $1.3 \mathrm{~g}$ are fired at velocities between 750 and $770 \mathrm{~m} / \mathrm{s}$ (Table 1). They represent fragments of a few grams projected at several hundred $\mathrm{m} / \mathrm{s}$ as the result of a detonation, but some similarities may be noticed with laboratory impact tests. On the one hand, the kinetic energy divided by the projectile section area can be similar (Table 1), and on the other, the loading type and the damage mechanisms may appear similar. In particular, since the projectiles are of high-strength steel, they suffer very little deformation, so their straight penetration creates a tunnel around which the material is heavily damaged. All around this tunnel, the abundant radial cracking propagates throughout the target, and the fore and rear faces of the target may be chipped off, depending on the thickness of the target $[13,14,18]$.

In parallel with these experimental studies, a great deal of numerical work has been done in the last 15 years in modelling the ballistic performance of 
concretes. This usually required data of the deviatoric strength of the concrete under strong hydrostatic pressure as well as of its compaction [19]. The behaviour of concretes under confined compression can be characterized by triaxial compression tests or by 'quasi-oedometric' (1D-strain) compression tests. In the triaxial compression tests, a pure hydrostatic pressure is first applied to a cylindrical specimen by a fluid and the cylinder is then subjected to axial compression (see the seminal works of Palaniswamy and Shah [20] and Kotsovos and Newman [21]). The deviatoric stress is then measured as a function of the axial strain under different confinement pressures, and the tests have shown the ductility of the concretes under strong confinement and the rising strength with the confinement pressure. For quasi-oedometric compression tests, a cylindrical specimen is placed inside a confinement cell. In the course of the axial compression, the diameter of the specimen tends to increase, and this leads to a higher lateral confinement pressure that can be registered by gauges attached to the outer surface of the cell. Then the axial stress, the deviatoric stress or the average stress can be deduced. Burlion [22] ran this type of test with three mortars of different water/cement ratios. The tests showed that the higher the proportion of water to cement, the greater was the increase in the compaction of the mortars (the diminution of the volume under strong confinement pressure) on account of the higher porosity at higher proportions of water to cement [23]. These tests confirmed that there is a close relation between the microstructure of the concretes and the behaviour under confined compression and that an essential parameter is the proportion of water/cement.

In this study, three-point bending tests and simple compression tests have been performed with two mortars in order to understand their damage under impact tests. Moreover, quasi-oedometric compression tests are included to analyse their performance under heavy confinement pressure. Their spherical and deviatoric behaviours are deduced from the tests and compared to those of a microconcrete of the MB50 type. Projectile impact tests on these two mortars are then described. A box-like set-up (named sarcophagus) surrounding the specimens is used to analyse the damage of the targets. The experimental work is supplemented by numerical simulations in which concrete is modelled with the Krieg, Swenson and Taylor model [24,25].

\section{Manufacturing, microstructure and density of the mortars}

\subsection{Composition of the mortars}

Two mortars were chosen, one with silica fume (M2) and the other without (M1). The composition of these mortars is given in Table 2, together with that of a mortar, MB50, considered as a reference [26] among the HPCs. The types M1 and M2 are therefore fine mortars with a weak water/ binder ratio (0.41-0.46) and a modest amount of sand
Table 2

Mix proportions of mortars M1, M2 and MB50 concrete

\begin{tabular}{lccc}
\hline & M1 & M2 & MB50 [26] \\
\hline Sand (quartz) $\left(\mathrm{kg} / \mathrm{m}^{3}\right)$ & 1366 & 1332 & 1783 \\
Silica fume $\left(\mathrm{kg} / \mathrm{m}^{3}\right)$ & 0 & 55.5 & 0 \\
Cement $\left(\mathrm{kg} / \mathrm{m}^{3}\right)$ & 569 & 555 & 400 \\
Water $\left(\mathrm{kg} / \mathrm{m}^{3}\right)$ & 260 & 253 & 200 \\
Admixture $\left(\mathrm{kg} / \mathrm{m}^{3}\right)$ & 4.7 & 4.6 & 12 \\
Water $/($ cement + silica fume) & 0.46 & 0.41 & 0.5 \\
Sand $/($ cement + silica fume) & 2.4 & 2.2 & 4.5 \\
Silica fume $/ \mathrm{cement}$ & 0 & 0.1 & 0 \\
Max grain size $(\mathrm{mm})$ & 0.5 & 0.5 & 5
\end{tabular}

(sand/binder $=2.2-2.4$ ). The cement pastes were poured into plywood moulds, M1 and M2 materials are selfconsolidating mortars so they were not submitted to vibration.

\subsection{Density of the mortars}

The density of the M1 and M2 mortars was measured with 12 bending samples taken from the centre of the block and therefore assumed to be representative of the compression and bending specimens used in the tests. This operation was performed with two different sets of samples, the results differing by less than $2 \%$. The density of the M1-type mortar (without silica fume) $\left(\rho_{\mathrm{M} 1}=2270 \mathrm{~kg} / \mathrm{m}^{3}\right)$ was seen to be higher than that of the M2 with silica fume $\left(\rho_{\mathrm{M} 2}=2180 \mathrm{~kg} / \mathrm{m}^{3}\right)$. This result is not really surprising considering the plot of distribution of pore sizes (Fig. 2) on which the millimetre-length porosity of M2 mortar appears larger than that of M1 mortar whereas the sub-millimetre-length porosity of each mortar is seen to be similar. The greater amount of porosity of the M2 mortar in comparison with that of the M1 seems to be singular since silica fume is known to increase the compressive strength of concretes (at least in the range of $0-15 \mathrm{wt} \%$ of cement replacement) [27,28]. However, increase of total pore volume with silica fume content has already been reported by Zelic et al. [29] (with an amount of water kept constant) in a mortar made with fine quartzsand aggregates and without limestone aggregates.

\section{Unconfined loadings (bending and simple compression tests)}

Both types of mortar were tested in three-point bending and simple compression to determine their tensile strength and their uniaxial compression strength. With each type, twenty bending tests and four uniaxial compression tests were performed and post-mortem observations were led. These data will be used in the final discussion to improve understanding of damage fields that are observed in the targets submitted to impact loading. 

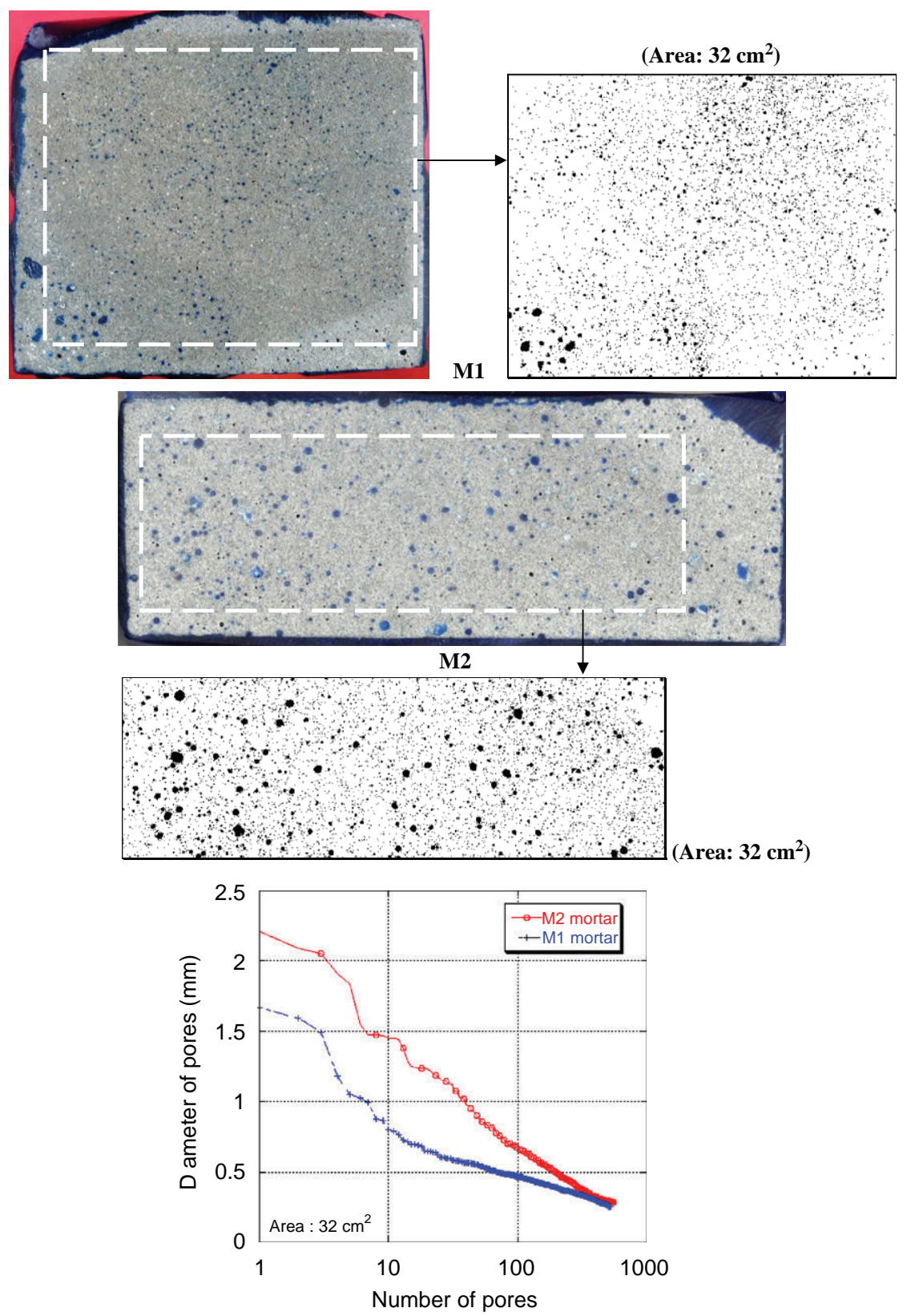

Fig. 2. Mesostructure of mortars M1 and M2 and distribution of pore sizes in an area of $32 \mathrm{~cm}^{2}$.

\subsection{Experimental set-up of the bending tests}

Samples of $20 \times 15 \times 100 \mathrm{~mm}^{3}$ were chosen so that their effective volume [30] would be similar to the characteristic volume of the impact tests (approximately projectile diameter to the power 3 ). The length between the supports was $l=80 \mathrm{~mm}$, which gave an $l / h$ ratio of 4 . The samples were taken from concrete blocks of $57-67 \mathrm{~mm}$ thickness. The surface tested in tension corresponds to the horizontal middle plane of these blocks. Each face was cut with a diamond saw and carefully polished to ensure smooth flat surfaces. The set-up of these tests is detailed in [31]. The central support was a straight linear contact and the two end supports were made of a point contact. This isostatic set-up ensures that no overstresses are introduced by any torsion loading. The extensometer rests directly on the specimen short-circuiting the deformation at the contact between the specimen and the supports (see the sketch of the experimental device on top of Fig. 3).

\subsection{Probabilistic approach used to analyse failure}

The failure that occurs in three-point bending tests is brittle and sharp. Several loading/unloading cycles were performed with specimens of $\mathrm{M} 1$ and $\mathrm{M} 2$ grades to measure the Young's modulus. No loss of stiffness was recorded before failure. So instable crack is thought to 


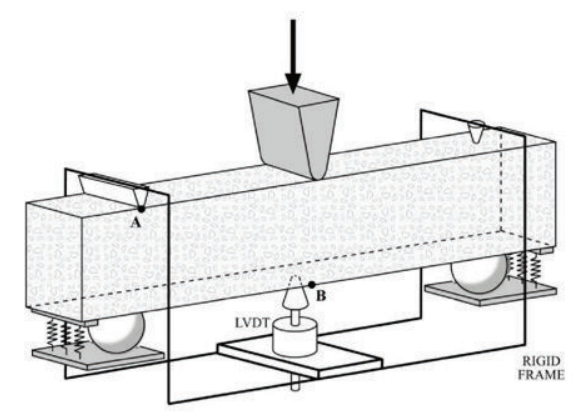

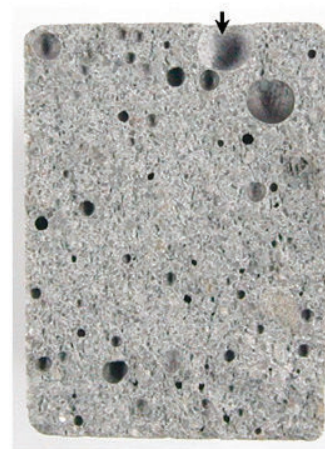

Specimen M2-LS

$\left(20.5 \times 15 \mathrm{~mm}^{2}\right)$

$\sigma_{\text {ultimatc }}=7.1 \mathrm{MPa}$

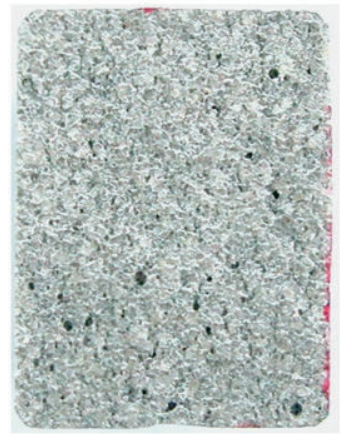

Specimen M1-LS

$\left(19.6 \times 15 \mathrm{~mm}^{2}\right)$

$\sigma_{\text {ultimate }}=6.8 \mathrm{MPa}$

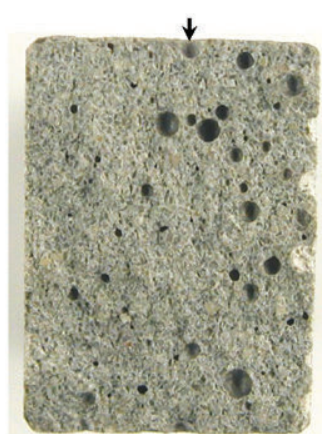

Specimen M2-MS $\left(20.0 \times 14.8 \mathrm{~mm}^{2}\right)$

$\sigma_{\text {ultimatc }}=8.8 \mathrm{MPa}$

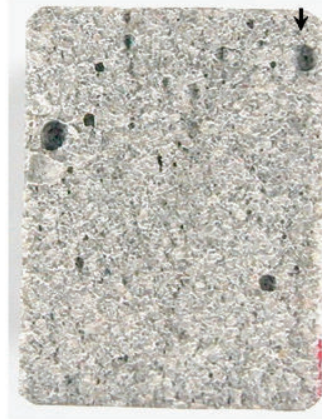

Specimen M1-MS $\left(19.7 \times 15 \mathrm{~mm}^{2}\right)$

$\sigma_{\text {ultimate }}=8.6 \mathrm{MPa}$

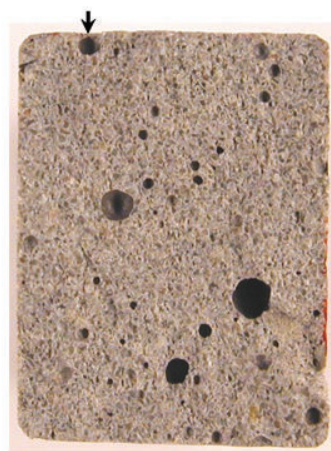

Specimen M2-HS

$\left(20.6 \times 15.5 \mathrm{~mm}^{2}\right)$

$\sigma_{\text {ultimate }}=10.6 \mathrm{MPa}$

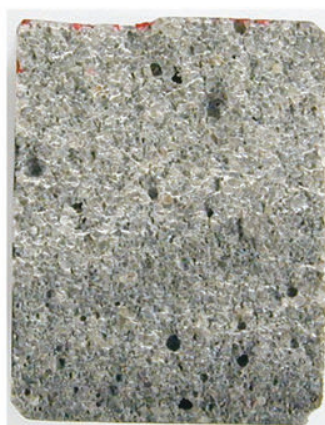

Specimen M1-HS

$\left(19.5 \times 15.5 \mathrm{~mm}^{2}\right)$

$\sigma_{\text {wltimate }}=10.6 \mathrm{MPa}$

Fig. 3. Top: sketch of three point bending device. Bottom: fracture surface of three M2 specimens and three M1 specimens after bending tests.

propagate in the specimen from the weakest defect of the specimen leading to its sudden failure. This is why the probability of failure of the samples may be described by the Weibull theory and is given by the following equation $[32,33]$ :

$P_{r}=1-\exp \left(-V_{\text {eff }} \lambda_{0}\left(\frac{\sigma_{\mathrm{m}}}{\sigma_{0}}\right)^{m}\right)$,

in which $\sigma_{\mathrm{m}}$ is the maximum principal stress in the sample before failure, $m$ is the Weibull modulus, and $\lambda_{0} / \sigma_{0}^{m}$ is the second Weibull parameter. The Weibull modulus shows whether the behaviour is probabilistic ( $m$ weak) or deterministic ( $m$ high). $V_{\text {eff }}$ is the effective volume, i.e., the volume the structure would have if the stress field in it was uniform (with the same probability of failure) [30]. The Weibull parameters can be identified from three-point bending tests, in which the effective volume is

$V_{\text {eff }}=\frac{V}{2(m+1)^{2}}$,

$V$ being the loaded volume of the specimen (i.e. the volume between the two supports). The effective volume is found to be heavily dependent on the Weibull modulus $m$. Of course the equivalent volume during a three-point bending test can be well below that of the total volume of the sample.

\subsection{Results of the bending tests}

From the results of the bending tests in Table 3, the average failure stress of $\mathrm{M} 1$ is seen to be slightly above that of the concrete with silica fume and the Weibull's moduli are almost identical $(m \approx 10)$. 
In Fig. 3 we see three different fracture surfaces (top region submitted to tensile stresses) of the two types of mortar, selected according to their failure stress (the weakest LS, the highest HS and an intermediate failure stress MS). The samples show a homogeneous material without inclusions. The apparent cause of failure is the presence of porosities larger than $1 \mathrm{~mm}$ in the type M2 $(2.7 \mathrm{~mm}$ for the LS-M2) and of less than $1 \mathrm{~mm}$ in the M1. This mortar is characterized by a lower average failure stress than that of the M2 while the porosities originating its failure are smaller: the cement matrix of the mortar with silica fume (M2) is intrinsically much more resistant than that of the M1, but that is partly offset by the size of its porosities.

\subsection{Simple compression tests}

Four simple compression tests were carried out with each type of mortar, using a hydraulic universal testing machine. The set-up of these tests is described in [31]. The samples were cut from blocks of $60-70 \mathrm{~mm}$ thickness and the surfaces were polished. The upper compression plate was mounted with a rotary link to the upper mobile crossbar so as to ensure a state of uniaxial stress on the sample. Elastic-brittle behaviour was observed throughout the tests.

\subsection{Results of the simple compression tests}

Table 3 presents the failure stresses in the M1 and M2 mortars under simple compression. As in the three-point

Table 3

Results of three point bending tests and simple compression tests

\begin{tabular}{lcc}
\hline Mortars & M2 & M1 \\
\hline Properties of mortars M1 and M2 after three point & bending tests \\
Young Modulus $E(\mathrm{GPa})$ & 34.0 & 33.0 \\
Average strength $\sigma_{\mathrm{w}}$ for & 8.86 & 8.21 \\
$V_{\mathrm{eff}}=100 \mathrm{~mm}^{3}(\mathrm{MPa})$ & & \\
Weibull's modulus $m$ & 10.2 & 12.4 \\
Numbers of specimens & 21 & 19 \\
Properties of mortars M1 and M2 after uniaxial compression tests \\
Failure stresses $(\mathrm{MPa})$ & $63.5 / 67.0 / 71.2 / 65.4$ & $40.8 / 56.05 / 69.8 / 70.6$ \\
Average strength $(\mathrm{MPa})$ & 66.8 & 59.3 \\
Number of specimens & 4 & 4 \\
\hline
\end{tabular}

bending tests, the average stress in the M2 mortar is slightly higher than in the M1. Fig. 4 shows the damage of three samples after failure - multiple cracking, axial or slightly oblique. The weakest failure stress in the M1 (40.8 MPa, Table 3) may be explained by an inclusion visible on the surface of fracture. Most of the cracks pass through the pores in the material. For example, the sample M2 shows a cone whose base corresponds to the circumference of the sample. The cone shows abundant porosity. The cracks are seen to start from the equator of these spherical pores. In fact, the pores are seen to split horizontally, not vertically, as is shown in the diagrams (see the "chimney-like crack" visible on the right-hand-side picture, white arrow). These observations indicate that the largest pores have likely caused a multiple cracking of the specimen and its collapse.

\section{Confined loading (quasi-oedometric compression tests)}

The principle of the quasi-oedometric compression test, of the method of processing, and of the validation of this method are presented elsewhere [34]. Tests with specimens of aluminium of known behaviour are described [34]. They showed the capacity of the experimental methodology to determine the behaviour of aluminium (Mises-type stress versus the equivalent strain). The methodology is based on evaluating the radial stress and strain in the specimen from hoop strains measured on the outer surface of the vessel (see the sketch of the experimental device on top of Fig. 5). The methodology of processing was applied at first to quasi-static and dynamic tests [35] that were performed by Gatuingt on MB50 microconcrete [36]. The analysis showed a very limited influence of the rate of loading on the strength, even at a strain rate that reached $400 \mathrm{~s}^{-1}$ [35].

Fig. 5 illustrates the results of the quasi-oedometric compression tests of the M1 and M2 mortars. The deviatoric behaviour of the two materials reveals a sharp rise of strength with the hydrostatic pressure. It reaches $368 \mathrm{MPa}$ (M2)-460 MPa (M1), comparable to that of the microconcrete (MB50) measured by a quasi-static quasioedometric compression test [35]. Above a pressure of about $320 \mathrm{MPa}$, the strength of M1 mortar becomes higher than that of M2. The strength of M2 is seen to reach its threshold above a pressure of $400 \mathrm{MPa}$ whereas that of M1

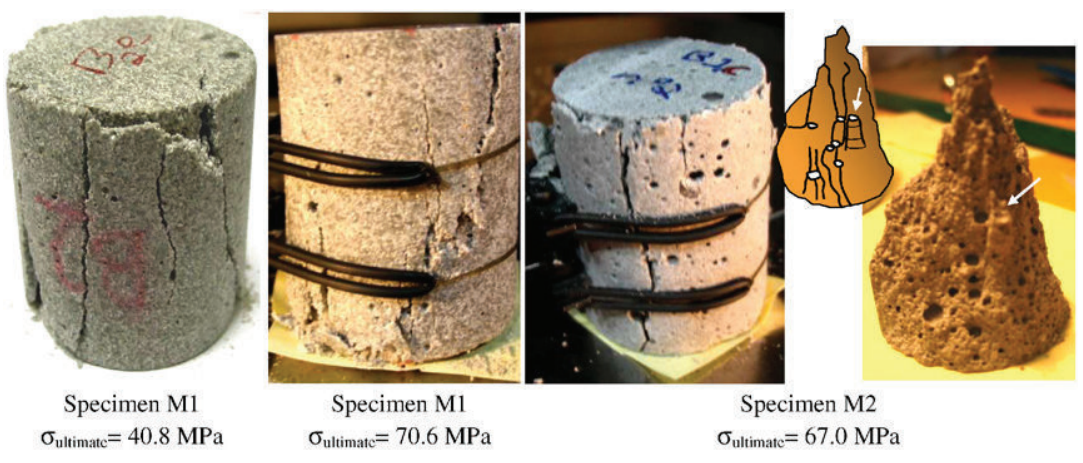

Fig. 4. Specimens M1 and M2 after failure, simple compression tests. 

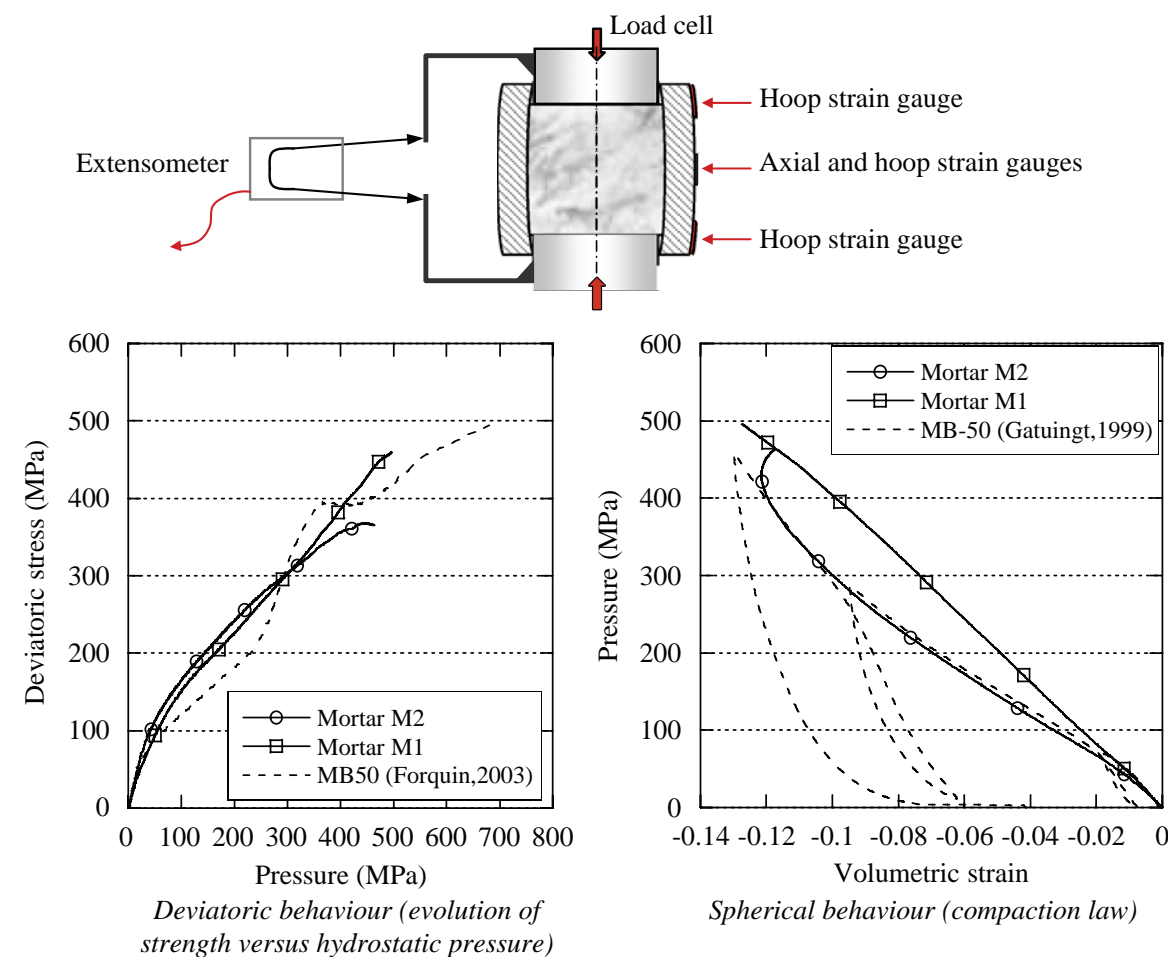

Fig. 5. Top: sketch of the device used for quasi oedometric compression tests. Bottom: experimental results obtained with mortars M1, M2 and compared with that of concrete MB50 [35,36].

mortar is still increasing up to $500 \mathrm{MPa}$ of pressure. In addition, the compaction (the diminution of the volume) of the M2 mortar is seen to be clearly greater than that of M1 (Fig. 5). Finally, the compaction curve of M2 mortar appears to be very close to that of MB50 concrete [36].

The macroscopic porosity of M2 illustrated in Fig. 2 (millimetre length in size) is supposedly the reason for these experimental findings. This porosity leads to a more rapid subsidence and a greater compaction that probably damages the material and lowers its strength under high pressure. Quasi-oedometric tests reveal a close link between macroscopic porosity (millimetre length) and the compaction of the material, even if the intrinsic resistance of the matrix is high, as shown in bending tests and under simple compression. The curve of the deviatoric behaviour also suggests a weaker deviatoric strength of M2 mortar under heavy confinement pressure than that of M1. This indicates a possible interaction between the deviatoric resistance and the spherical behaviour of these mortars under high pressure. In the present case, the mortars had not been vibrated resulting in a millimetre-length porosity of M2 above that of M1 as shown in Fig. 2. The difference of pore size distribution of the mortars may explain the easiest compaction of M2 mortar in comparison with that of M1.

\section{Projectile impact tests}

Tests were run with a SABRE light-gas gun. The targets were placed in airtight aluminium boxes (that we will call sarcophagus) that captured all the fragments of the target so the cracking patterns suffered neither erosion nor deterioration. After impact, the targets were infiltrated under vacuum with a coloured hyperfluid resin. The postmortem observations (depth of penetration of the projectile, damage to the target) were made after the soaked targets had been cut and polished. These tests made it possible not only to determine the ballistic qualities of the target (the depth of penetration) but also to observe the damage (the size of the crater, the cracking, spalling, and fragmentation of the targets).

Impact tests are analysed according to five parameters: the depth of penetration of the projectile into the target, the damage around the point of impact, the cracking or dynamic fragmentation of the impacted targets, the state of the projectile (its deformation, erosion or imbalance) and the influence of the type of front boundary condition.

\subsection{Experimental set-up}

The impact device is seen at the left in Fig. 6. It consists of a gas gun (on the left), then a rectangular passage in which optic barriers provide a measurement of the speed of the projectile [37], and a second chamber (on the right) enclosing the target. The cylindrical projectiles, fired at between 750 and $770 \mathrm{~m} / \mathrm{s}$, are of rolled 100C6 steel, of $8 \mathrm{~mm}$ length, $5.3 \mathrm{~mm}$ diameter and a mass of $1.3 \mathrm{~g}$. Measurements of their surface hardness gave a very high value of 65 

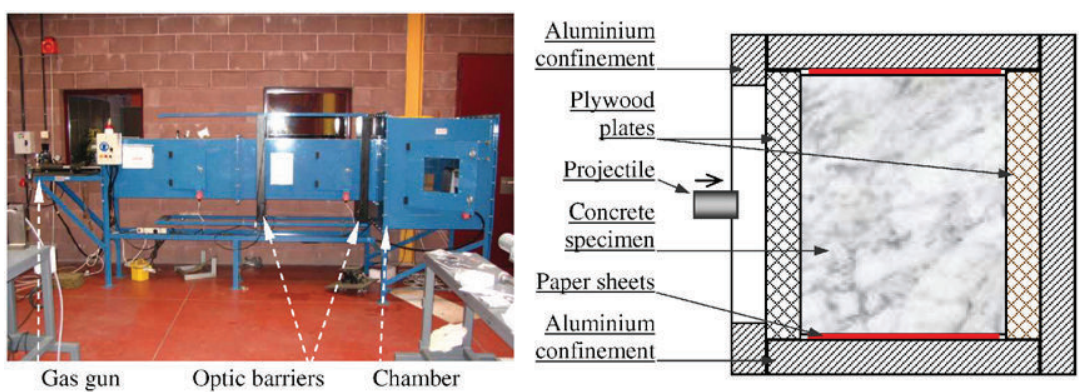

Fig. 6. Gas gun and sarcophagus set up used for the impact test.

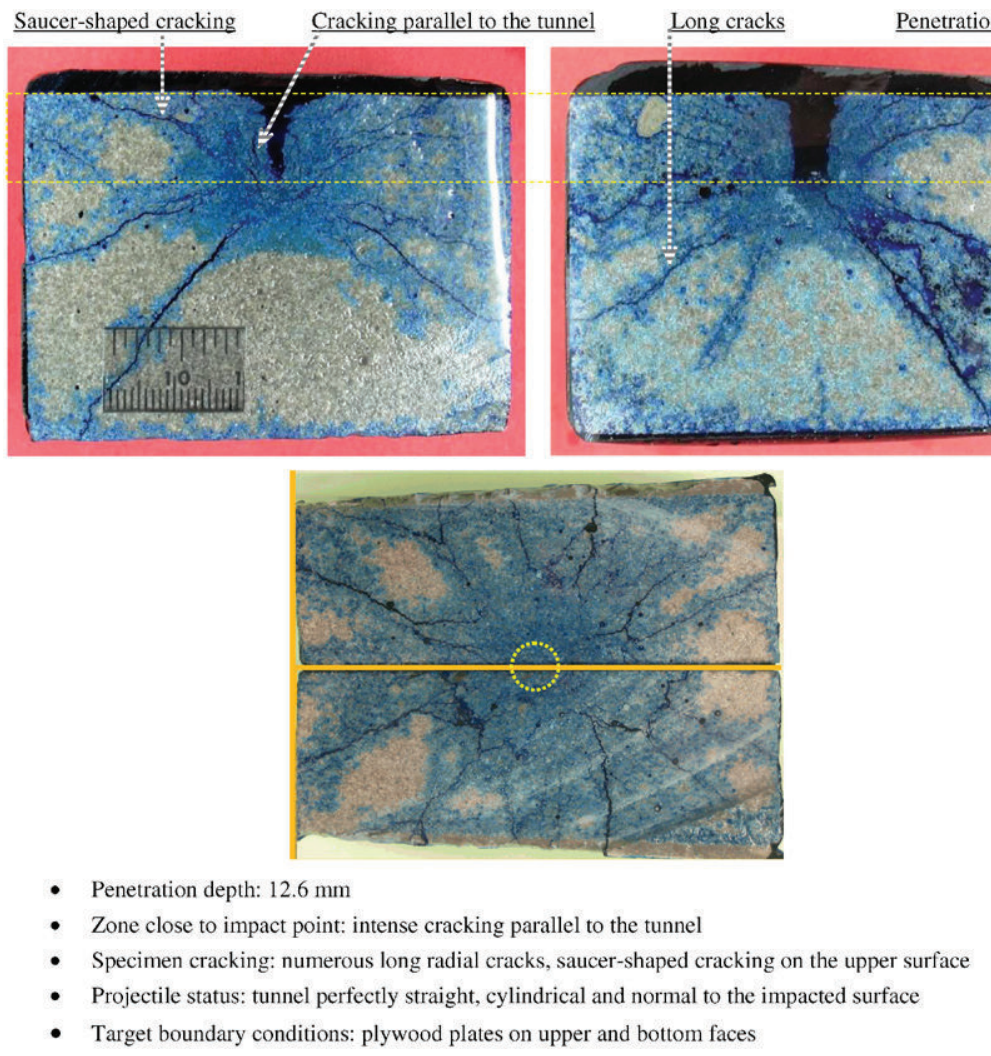

Fig. 7. Impact of projectile onto M1 mortar $(765 \mathrm{~m} / \mathrm{s})$ (cutting width: $3 \mathrm{~mm}$ ). Top: cross section along impact axis; bottom: cross section at the level of maximum penetration and perpendicular to the impact axis.

Vickers but the internal hardness was not measured in this study and may be lower.

At the right of Fig. 6 we see a sketch of the sarcophagus configuration. Two plywood plates are attached to the concrete block, one on the front surface and one at the rear. The front plate restrains any erosion of the target without modifying the impact velocity, and the rear plate provides a breakage stress between the specimen and the confinement due to its lower mechanical impedance, ensuring a fragmentation equivalent to that of a free-standing block while preventing any movement of the fragments of the target. The dimensions of the concrete block $\left(70 \times 70 \times 50 \mathrm{~mm}^{3}\right)$ are the maximum acceptable for the placing of the impacted target in the Epovac infiltration chamber (diameter of the chamber
$130 \mathrm{~mm}$ ). The following illustrations show the results of the post-mortem studies.

\subsection{Results of the impact tests}

Fig. 7 shows the result of an impact test on a type-M1 mortar. The tunnel created by the projectile is perfectly straight and at right angles to the impacted surface, so the trajectory of the projectile is straight and steady. In Fig. 7 and in the subsequent illustrations, the projectile is not visible; it went into the target and was found intact in the inside of the chamber, a further proof of the axial symmetry of the shot. Three different types of damage are visible, the first near the tunnel. It is composed of a material totally microcracked and compacted that spreads 
over $5-7 \mathrm{~mm}$ from the tunnel. A crack is visible in this zone, parallel to the tunnel, evidently the effect of intense shear deformation under heavy pressure.

The second damage consists of long cracks right across the target. As they are the consequence of hoop stresses induced by the radial motion of the material that follows the compressive wave, they are usually oriented in radial planes containing the axial direction and are well observed in the cross-section perpendicular to the impact axis.

The third damage is that of the saucer-shaped cracking on the front surface, the result of heavy compression in the direction orthogonally oriented to the axis of the tunnel, which provokes a cone-like expulsion of the material on the front surface. This abundant cleavage appears to be little affected by the presence of the plywood plate.

Fig. 8 shows the same test as that of Fig. 7 but without using the front plywood during the test. The maximum depth of the shattering of the concrete is seen to go slightly beyond the depth of penetration of the projectile in the preceding example- $16.2 \mathrm{~mm}$ as compared to $12.6 \mathrm{~mm}-$ although the actual depth of penetration into the target is difficult to evaluate as the tunnel cannot be seen. So the use of the plywood gives more complete information of the damage close to the point of impact. Moreover, the cracking pattern within the target and the plate-like surface cracks seem to be very similar to those of the previous case
(Fig. 7). Impact tests were also achieved with aluminium alloy targets with and without the plywood. The depth of penetration of the projectile into the target was the same. It can be assumed, therefore, in the following tests that this front plate does not affect the depth of penetration.

In Figs. 9 and 10 we see the result of the impact tests performed on M2 mortar. Again the tunnel created in the target is straight and perpendicular to the impacted surface. The depth of penetration of the projectile into the target is about $15 \mathrm{~mm}$, a little more than with M1 mortar. This may be due to the greater porosity of M2 (on a millimetre-length scale) as observed on the surfaces in the tests under simple compression and three-point bending tests. The quasi-oedometric compression tests also emphasized the part played by this porosity in the performance under confined compression. In fact these tests showed a greater compaction of M2 mortar under heavy pressure even though the resistance under confined compression was similar to that of M1. Impact of a projectile implies, of course, a state of confined compression around the projectile, so the result of these impact tests is coherent with that of the preceding quasi-oedometric compression tests.

The damage to the M2 specimens is similar to that observed in M1. A zone of microcracks near the tunnel, long radial cracks in the block, and a plate-like area of
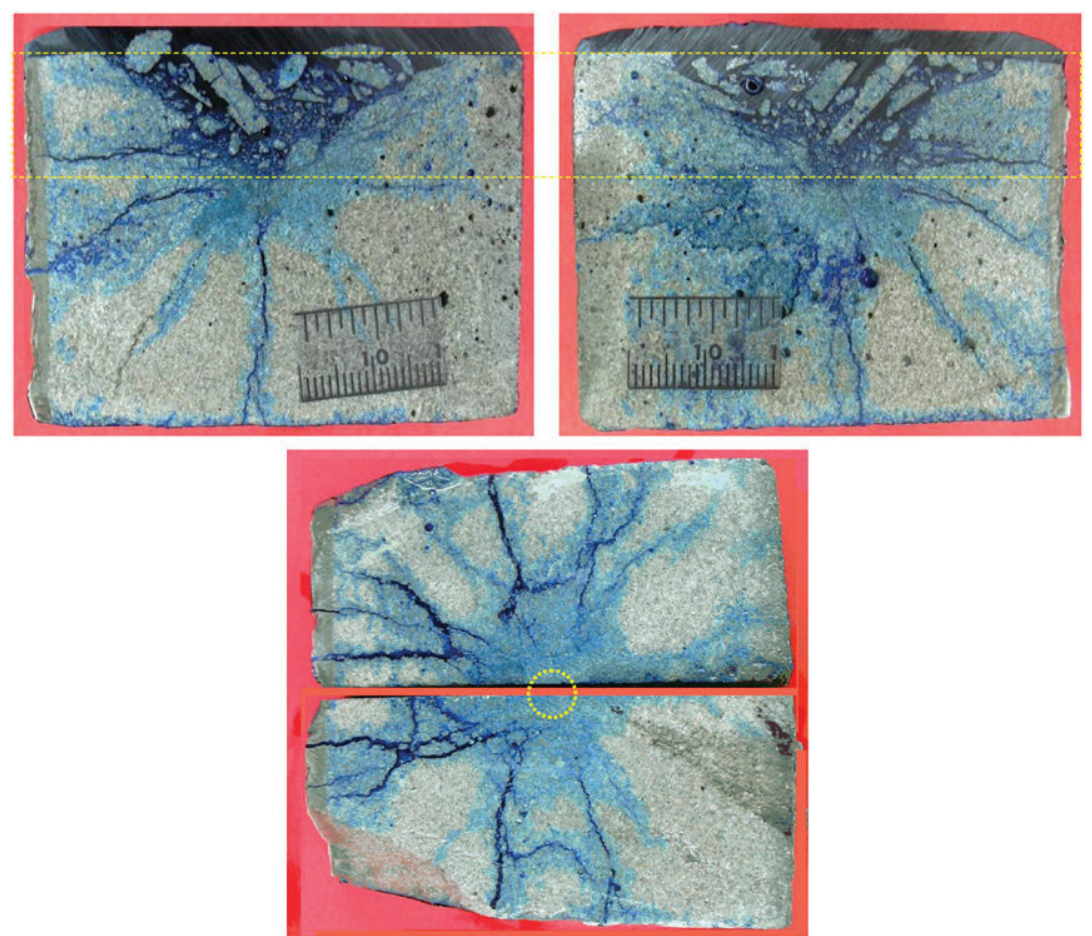

- Penetration depth or erosion depth: $16.2 \mathrm{~mm}$

- Zone close to impact point: zone reduced to debris

- Specimen cracking: numerous long radial cracks, strong damage on the upper surface

- Projectile status: unknown

- Target boundary conditions: no plywood plate on upper face but plywood plate on bottom face

Fig. 8. Impact of projectile onto M1 mortar without frontal plywood ( $765 \mathrm{~m} / \mathrm{s}$ ) (cutting width: $3 \mathrm{~mm})$. Top: cross section along impact axis; bottom: cross section at the level of maximum penetration and perpendicular to the impact axis. 

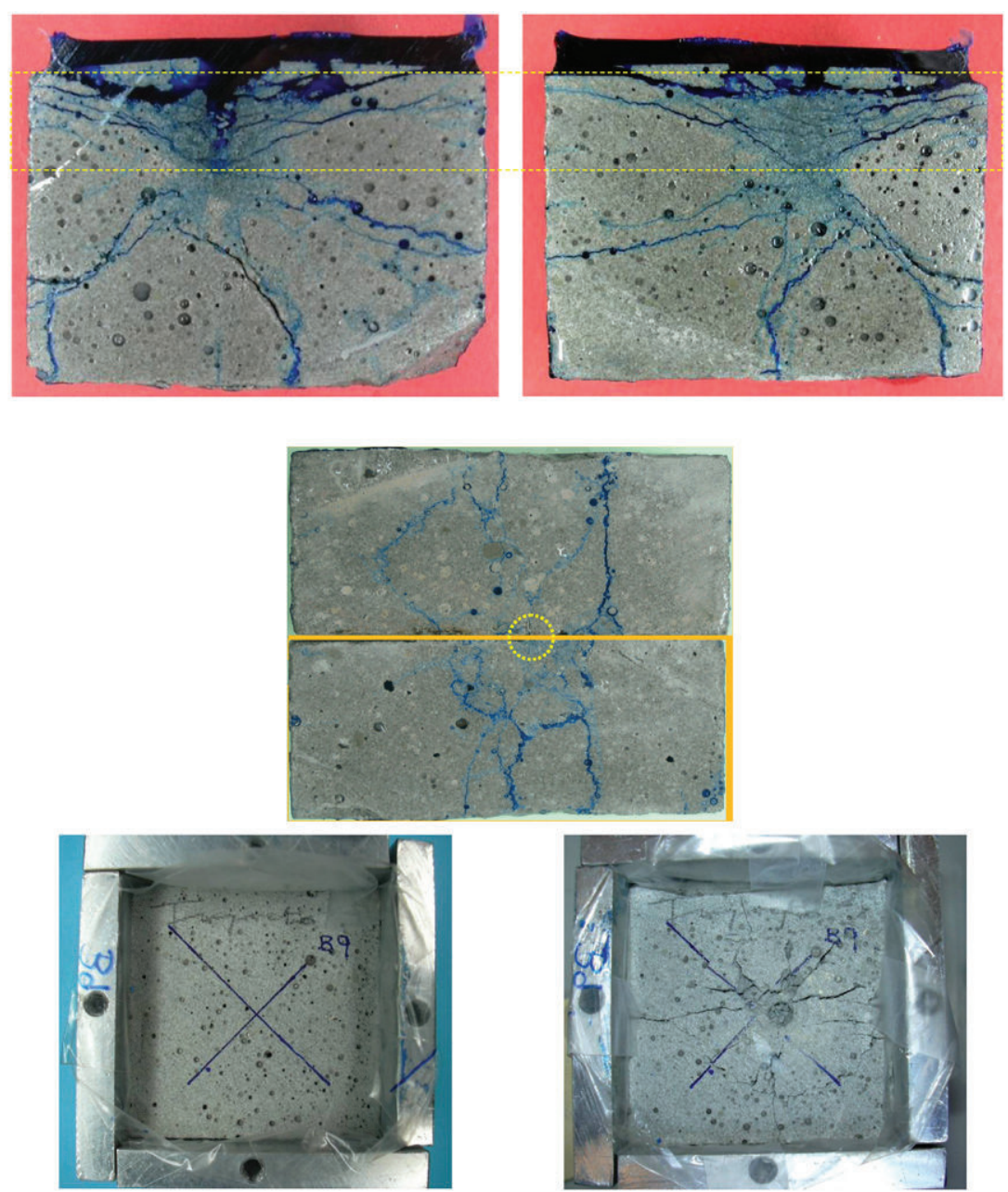

- Penetration depth: $14.9 \mathrm{~mm}$

- Zone close to impact point: intense micro-cracking

- Specimen cracking: numerous long radial cracks

- Projectile status: tunnel perfectly straight and normal to the impacted surface

- Target boundary conditions: plywood plates on upper and bottom faces

Fig. 9. Impact of projectile onto M2 mortar $(762 \mathrm{~m} / \mathrm{s}$ ) (cutting width: $3 \mathrm{~mm}$ ). Top: cross section along impact axis; middle: cross section at the level of maximum penetration and perpendicular to the impact axis; bottom: frontal view of the specimen before and after the test.

cracking extending some $50 \mathrm{~mm}$ on the front surface forming a large number of horizontal cracks in Figs. 9 and 10. A number of cracks radiating from the point of impact are visible at the lower right hand of Fig. 10.

\section{Numerical simulation of the impact tests}

\subsection{Modelling of the behaviour of the mortars}

Two numerical simulations of the impact tests were made with the Abaqus/Explicit FE code [38] using the model for concrete of Krieg, Swenson and Taylor [24,25]. This model describes the spherical behaviour by a compaction law that links the volumetric strain to the hydrostatic pressure. The curve is defined with several points $\left(\varepsilon_{v}^{i}, P_{i}\right)$. The hydrostatic pressure is given by interpolation between these points according to the expression:

$$
P\left(\varepsilon_{v}\right)=P_{i} 1 \frac{\varepsilon_{v}-\varepsilon_{v}^{i}}{\varepsilon_{v}^{i} 1-\varepsilon_{v}^{i}}+P_{i} \frac{\varepsilon_{v}-\varepsilon_{v}^{i}{ }^{1}}{\varepsilon_{v}^{i}-\varepsilon_{v}^{i}{ }^{1}} \quad \text { for } \quad \varepsilon_{v}^{i}{ }^{1}>\varepsilon_{v}>\varepsilon_{v}^{i} .
$$

This law is accompanied by a limitation of the Von Mises stress as a function of the hydrostatic pressure $P$ (perfect plasticity):

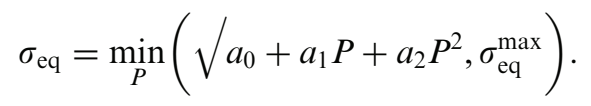

The various coefficients $\left(a_{0}, a_{1}, a_{2}, \sigma_{\mathrm{eq}}^{\max }, \varepsilon_{v}^{i}, P_{i}\right)$ were identified by means of the quasi-oedometric compression tests of Fig. 5. The curves used to identify the parameters and the coefficients are given, respectively, in Fig. 11 and in 

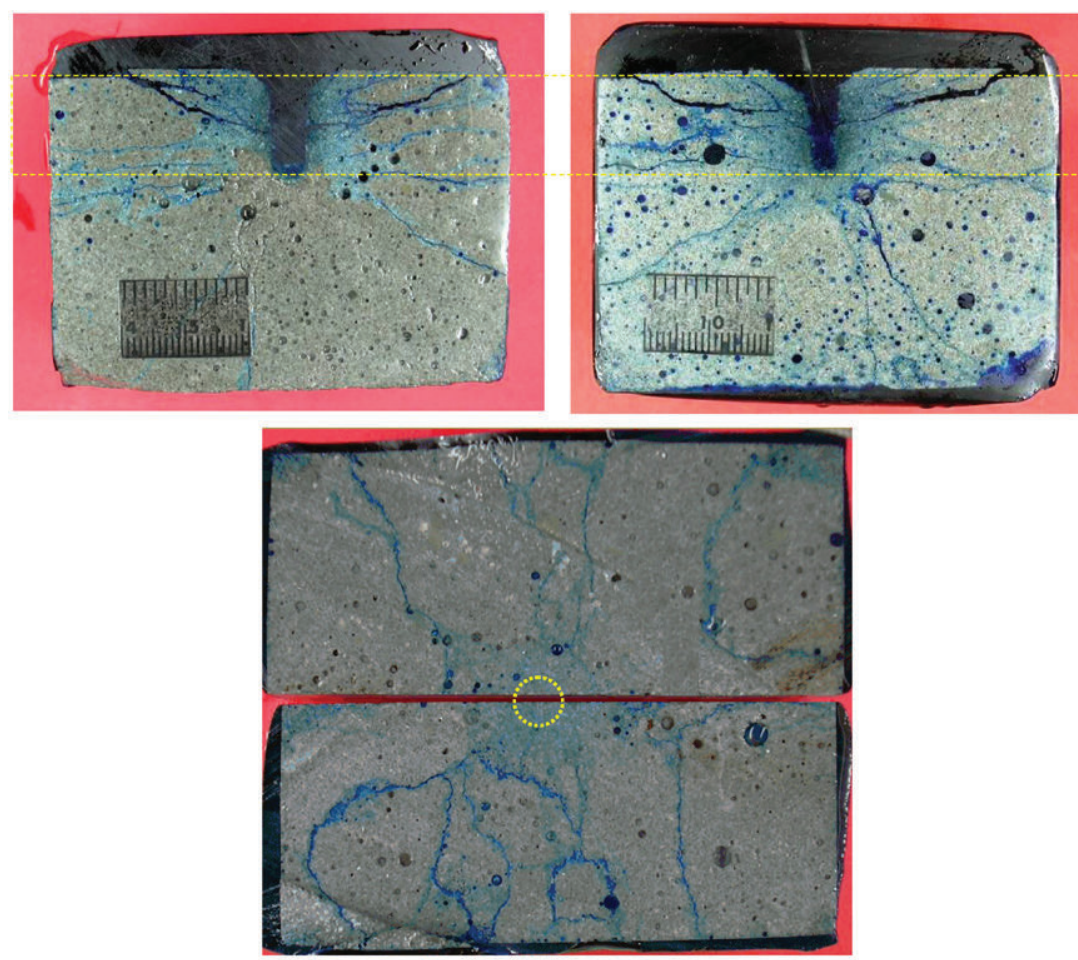

- Penetration depth: $15.1 \mathrm{~mm}$

- Zone close to impact point: intense micro-cracking along the tunnel

- Specimen cracking: numerous long radial cracks and a saucer-shaped cracking on the upper surface

- Projectile status: tunnel perfectly straight, cylindrical and normal to the impacted surface

- Target boundary conditions: plywood plates on upper and bottom faces

Fig. 10. Impact of projectile onto M2 mortar $(765 \mathrm{~m} / \mathrm{s}$ ) (cutting width: $3 \mathrm{~mm}$ ). Top: cross section along impact axis; bottom: cross section at the level of maximum penetration and perpendicular to the impact axis.

Table 4

Parameters of the Krieg, Swenson and Taylor model for the two mortars

\begin{tabular}{lll}
\hline Mortars & M2 & M1 \\
\hline Density $(\rho)$; elastic coefficients $(E$ and $v)$ & $2.18,34 \mathrm{GPa}, 0.2$ & $2.27,33 \mathrm{GPa}, 0.2$ \\
Deviatoric law $\left(a_{0}, a_{1},, a_{2}, \sigma_{\text {eq }}^{\max }\right)$ & $625 \mathrm{MPa}^{2}, 253 \mathrm{MPa}, 0.16,368 \mathrm{MPa}$ & $625 \mathrm{MPa}^{2}, 150 \mathrm{MPa}, 0.56,500 \mathrm{MPa}$ \\
Spherical law $\left(\varepsilon_{v}^{(1)}, P^{(1)}, \quad \varepsilon_{v}^{(2)}, P^{(2)}, \quad \varepsilon_{v}^{(3)}, P^{(3)}\right)$ & $0.06 \%, 11.7 \mathrm{MPa}$, & $0.06 \%, 11.7 \mathrm{MPa}$, \\
& $9.4 \%, 273 \mathrm{MPa}$, & $8.4 \%, 343 \mathrm{MPa}$, \\
& $14 \%, 464 \mathrm{MPa}$ & $12.5 \%, 496 \mathrm{Mpa}$ \\
\hline
\end{tabular}

Table 4. The plastic strain tensor $\mathbf{e}^{\mathrm{p}}$ is defined as

$\mathbf{e}^{\mathrm{p}}=\mathbf{e}-\frac{s}{2 G}$,

where $\mathbf{e}$ is the deviatoric part of the total strain tensor, $\mathbf{s}$ the deviatoric stress tensor, and $G$ the shear modulus. The plastic strain increment de $\mathbf{e}^{\mathrm{p}}$ is given by

$\mathrm{de} \mathbf{e}^{\mathrm{p}}=\mathrm{d} \lambda \frac{\partial \phi_{\mathrm{s}}}{\partial \mathbf{s}}$

$\phi_{\mathrm{s}}$ being a non associated plastic potential given by $\phi_{\mathrm{s}}=\sigma_{\mathrm{eq}}$.

An axisymmetric numerical simulation of the impact tests carried out with the KST model is shown in Fig. 12. Four nodes reduced integration elements (CAX4R in Abaqus notation) are used. A method of erosion allows the removal of elements and a simulation of the penetration of the projectile into the target. This method and the meshing were validated by an impact test on an aluminium alloy as well as by experimental results. The erosion criterion is an equivalent plastic deformation of the elements of $200 \%$, which is common in problems of impact penetration of concretes [39]. The depth of penetration (computed as the maximum depth of penetration of the projectile) into the M2 target was $14.4 \mathrm{~mm}$ (Fig. 12, lefthand side), roughly the same as in the impact tests $(15 \mathrm{~mm}$, Figs. 9 and 10). Penetration of the M1 mortar is slightly overestimated, the tunnel generated by simulation being $13.2 \mathrm{~mm}$ (Fig. 12, right hand) against the $12.6 \mathrm{~mm}$ of the experimental finding (Fig. 7).

The same calculations made with an erosion criterion of $150 \%$ give a tunnel depth of $15.9 \mathrm{~mm}$ for M2 mortar and of 


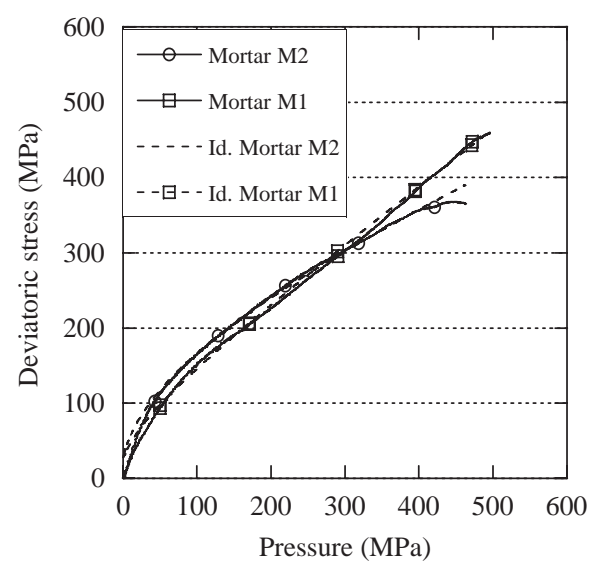

Deviatoric behaviour (evolution of strength versus hydrostatic pressure)

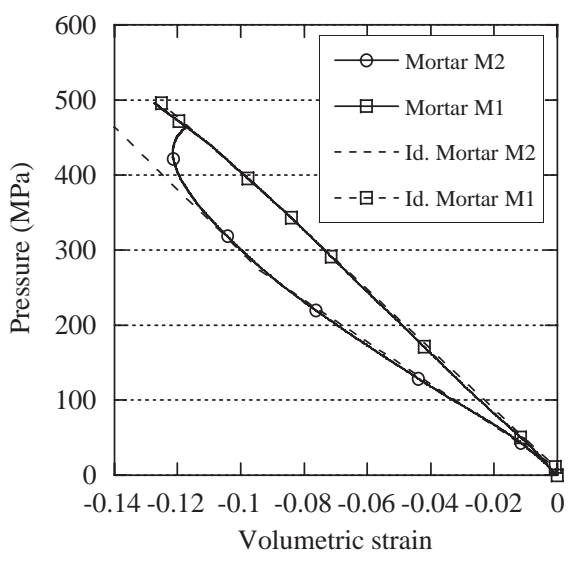

Spherical behaviour (compaction law)

Fig. 11. Fitting the KST model parameters with the deviatoric and spherical behaviours of mortars M1 and M2. (“Id." curves: curves identified for the KST model).

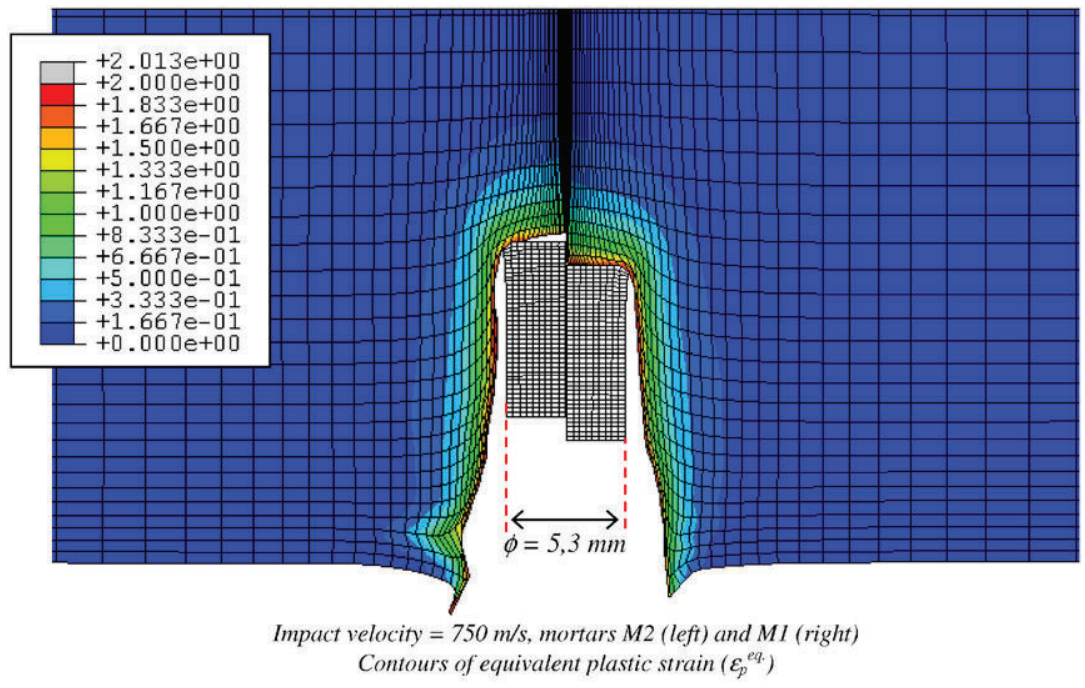

Fig. 12. Numerical simulations of the impact test using the KST model (parameters identified from Fig. 11).

$14.6 \mathrm{~mm}$ for M1. Really it appears that the erosion criterion makes only a slight change in the results of the numerical simulation. A study of the sensitivity to the meshing again showed no significant change in these results, so the calculations reiterate the scale of the penetration depth (a tunnel of about $15 \mathrm{~mm}$ long). The numerical simulations reveal the different ballistic performances of the two mortars, but lesser than the experimental results. The volumetric strain shown in the target by the simulations around the projectile is between $5 \%$ and $15 \%$, which confirms the need to identify the spherical law over a sufficiently wide range.

\section{Conclusion}

On one hand, the porosity distribution of the mortars (density and size of pores) is seen to influence directly their performances (unconfined strength, confined strength, compaction, depth of penetration). For example, in the performance of the two mortars under tension, simple compression or slight confinement, millimetre-length porosity is found to weaken the mortar with silica fume but not enough to lower its resistance to below that without it. In the performance of the two mortars under confined compression and impact loadings, the porosity of the mortar with silica fume implies a compaction of the matrix with the collapse of the pores leading to its lower deviatoric strength and its higher compaction in comparison with the mortar without silica fume when pressure is higher than $300 \mathrm{MPa}$. This result explains the better ballistic performance (lower depth of penetration) of the mortar without the siliceous additive. The numerical simulations by the KST (Krieg, Swenson and Taylor) model are able to release the link between the mechanical behaviour under slight and strong confinement, and the ballistic performance (depth of penetration) of the two materials. 
On the other hand, post-mortem observations of three point bending tests, simple compression tests and ballistic impact tests were achieved showing that porosity of the two mortars originated most probably the unconfined damage (crack-opening mode). A single crack is initiated at failure for bending tests, several axial cracks are generated under uniaxial compression loading and a multiple fragmentation made of numerous oriented cracks is visible under ballistic impact tests. The cracking patterns of both types of mortars are found to look alike, that is in agreement with the similarity of Weibull's parameters of the two materials. However, the damage patterns observed close to the tunnel is composed of an intense microcracking that was not observed under unconfined tests (bending and simple compression). Probably due to the high depth of penetration in comparison with the calibre of the projectile, the depth of penetration reflected certainly better the behaviour of the materials under high pressure measured with quasi-oedometric compression tests than that under unconfined loadings.

\section{Acknowledgements}

The authors are indebted to the Spanish Comisión Interministerial de Ciencia y Tecnología (Project MAT2002-03339) for the financial support of this work and to the Délégation Générale pour l'Armement (DGA/ France) for the mobility grant provided to Dr. Forquin.

\section{References}

[1] Hewish M. Adding new punch to cruise missile. Jane's Int Defense Rev 1998;40 5.

[2] Malier Y. Les bétons à hautes performances. France: Presses de l'Ecole Nationale des Ponts et Chaussées; 1992.

[3] Cheyrezy M, Maret V, Frouin L. Microstructural analysis of RPC. Cem Concr Res 1995;25(7):1491 500.

[4] Darrigade A, Buzaud E. High performance concrete: a numerical and experimental study. In: Proceedings of the ninth international symposium on the interactions of the effects of munitions with structures. Berlin, 1999.

[5] Forrestal MJ, Altman BS, Cargile JD, Hanchak SJ. An empirical equation for penetration depth of ogive nose projectiles into concrete targets. Int J Impact Eng 1994;15:395 405.

[6] Forrestal MJ, Frew DJ, Hanchak SJ, Brar NS. Penetration of grout and concrete targets with ogive nose steel projectiles. Int J Impact Eng 1996;18:465 76.

[7] Frew DJ, Hanchak SJ, Green ML, Forrestal MJ. Penetration of concrete targets with ogive nose steel rods. Int J Impact Eng 1998; 21:489 97

[8] Gomez JT, Shukla A. Multiple impact penetration of semi infinite concrete. Int J Impact Eng 2001;25:965 79.

[9] Kennedy RP. A review of procedures for the analysis and design of concrete structures to resist missile impact effects. Issue Series Title: Nucl Eng Des 1976;37:183 203.

[10] Barr P. Guidelines for the design and assessment of concrete structures subjected to impact. London: Atomic Energy Authority; 1990.

[11] Piekutowski AJ, Forrestal MJ, Poormon KL, Warren TL. Penetra tion of 6061 T6511 aluminum targets by ogive nose steel projectiles with striking velocities between 0.5 and $3.0 \mathrm{~km} / \mathrm{s}$. Int $\mathbf{J}$ Impact Eng 1999;23(1):723 34 .
[12] Forrestal MJ, Piekutowski AJ. Penetration experiments with 6061 T6511 aluminum targets and spherical nose steel projectiles at striking velocities between 0.5 and $3.0 \mathrm{~km} / \mathrm{s}$. Int $\mathbf{J}$ Impact Eng 2000;24:57 67

[13] Li QM, Reid SR, Wen HM, Telford AR. Local impact effects of hard missiles on concrete targets. Int J Impact Eng 2005;32: 22484.

[14] Hanchak SJ, Forrestal MJ, Young ER, Ehrgott JQ. Perforation of concrete slabs with 48 and $140 \mathrm{MPa}$ unconfined compressive strengths. Int J Impact Eng 1992;12(1):1 7.

[15] Yankelevsky DZ, Dancygier AN. Uniaxial compressive strength effect on high velocity penetration into thick NSC and HSC targets. In: Proceedings of symposium ISIEMS. 2001.

[16] Holmquist TJ, Johnson GR, Cook WH. A computational constitu tive model for concrete subjected to large strains, high strain rates, and high pressures. In: proceedings of the 14th international symposium on ballistics. Québec, 1993.

[17] Forrestal MJ, Frew DJ, Hickerson JP, Rohwer TA. Penetration of concrete targets with deceleration time measurements. Int J Impact Eng 2003;28:479 97.

[18] Frew DJ, Forrestal MJ, Cargile JD. The effect of concrete target diameter on projectile deceleration and penetration depth. Int $\mathbf{J}$ Impact Eng 2006;32:1584 94.

[19] Schwer LE, Day J. Computational techniques for penetration of concrete and steel targets by oblique impact of deformable projectiles. Nucl Eng Des 1991;125:215 38.

[20] Palaniswamy R, Shah SP. Fracture and stress strain relationship of concrete under triaxial compression. J Struct Div 1974;100(5): 90116.

[21] Kotsovos MD, Newman JB. Mathematical description of deforma tional behavior of concrete under generalized stress beyond ultimate strength. J Am Concr Inst ACI 1980;77:340 6.

[22] Burlion N. Compaction des bétons: éléments de modélisation et caractérisation expérimentale. $\mathrm{PhD}$ dissertation, Ecole Normale Supérieure de Cachan, France, 1997.

[23] Burlion N, Pijaudier Cabot G, Dahan N. Experimental analysis of compaction of concrete and mortar. Int $\mathrm{J}$ Num Anal Methods Geomech 2001;25:1467 86 .

[24] Krieg RD. A simple constitutive description for soils and crushable foams. In: SC DR 7260883 report, Sandia National Laboratory, Alburqueque, 1978.

[25] Swenson DV, Taylor LM. A finite element model for the analysis of tailored pulse stimulation of boreholes. Int J Num Anal Methods Geomech 1983;7:469 84.

[26] Toulemonde F. Résistance au choc des structures en béton: Du comportement des matériaux au calcul des ouvrages. PhD disserta tion, Ecole Nationale des Ponts et Chaussées, France, 1994.

[27] Bhanja S, et Sengupta B. Influence of silica fume on the tensile strength of concrete. Cem Concr Res 2005;35:743 7 .

[28] Atis CD, Ozcan F, Kiliç A, Karahan O, Bilim C, Severcan MH. Influence of dry and wet curing conditions on compressive strength of silica fume concrete. Build Environ 2005;40(12):1678 83.

[29] Zelic J, Krstulovic R, Tkalcec E, Krolo P. The properties of Portland cement limestone silica fume mortars. Cem Concr Res 1999;30: 14552.

[30] Davies DGS. The statistical approach to engineering design in ceramics. Proc Brit Ceram Soc 1973;22:429 52.

[31] Arias A, Forquin P, Zaera R, Navarro C. Relationship between static bending and compressive behaviour of particle reinforced cement composites. Compos Part B Eng 2007; submitted for publication.

[32] Weibull W. A statistical theory of the strength of materials. Report 151, Royal Swedish Institute of Engineering Research, 1939

[33] Weibull W. A statistical distribution function of wide applicability. ASME J Appl Mech 1951;18(3):293 7.

[34] Forquin P, Arias A, Zaera R. An experimental method of measuring the confined compression strength of geomaterials. Int $\mathrm{J}$ Solids Struct, in press, doi:10.1016/j.ijsolstr.2006.11.022. 
[35] Forquin P. Endommagement et fissuration de matériaux fragiles sous impact balistique, rôle de la microstructure. PhD dissertation, Ecole Normale Supérieure de Cachan, France, 2003.

[36] Gatuingt F. Prévision de la rupture des ouvrages en béton sollicités en dynamique rapide. PhD dissertation, Ecole Normale Supérieure de Cachan, France, 1999.
[37] Arias A, Zaera R, López Puente J, Navarro C. Numerical modeling of the impact behavior fo new particulate loaded composite. Compos Struct 2003;2:151 9 .

[38] Hibbitt HD, Karlsson BI, Sorensen P. Abaqus user's manual. ABAQUS/EXPLICIT 6.1, 2003.

[39] Buzaud E. Les têtes explosives. Charges à éclats et à effets de soufflé., SAE report, France, 2002. 